\title{
Gender patterns in Vietnam's child mortality
}

\author{
Thong Le Pham • Peter Kooreman • \\ Ruud H. Koning • Doede Wiersma
}

Received: 28 February 2011 / Accepted: 14 May 2012 /

Published online: 19 June 2012

(C) The Author(s) 2012. This article is published with open access at Springerlink.com

\begin{abstract}
We analyze child mortality in Vietnam focusing on gender aspects. Contrary to several other countries in the region, mortality rates for boys are substantially larger than for girls. The mortality rate of boys appears to be more sensitive to parents' education levels than the mortality rate of girls. A high education level of the father is particularly protective for boys. The ruralurban mortality difference in the raw data, which is particularly large for boys, can be fully explained by differences in observable characteristics of urban and rural households.
\end{abstract}

Keywords Child mortality $\cdot$ Gender differences $\cdot$ Hazard rate $\cdot$ Frailty model

JEL Classification $\mathrm{C} 13 \cdot \mathrm{C} 31 \cdot \mathrm{C} 35 \cdot \mathrm{C} 41 \cdot \mathrm{I} 12$

\section{Introduction}

Researchers in demography, public health, and population economics have documented the remarkably low child mortality levels in Vietnam compared

Responsible editor: Junsen Zhang

T. L. Pham

School of Economics and Business Administration (SEBA), Cantho University, Campus II, 3/2 Street, Ninh Kieu District, Cantho, Vietnam

P. Kooreman $(\bowtie)$

Department of Economics, Tilburg University, P.O.B. 90153,

5000LE Tilburg, The Netherlands

e-mail: p.kooreman@uvt.nl

R. H. Koning · D. Wiersma

Department of Economics, Econometrics \& Finance, University of Groningen,

P.O.B 800, 9700AV Groningen, The Netherlands 
to other countries in the same region with similar income levels (see, e.g., Nguyen-Dinh and Feeny (1999) and Wagstaff and Nga (2002)). Previous studies also reported large persistent differences between child mortality rates in rural versus urban areas. Work by O'Donnell et al. (2009) and others suggests that these differences are related to rural-urban gaps in nutritional status, income, and parental education.

While most researchers have allowed for possible gender differences in mortality rates by including a gender dummy in their empirical models, gender patterns have not been a central research question. ${ }^{1}$ Wagstaff and Nga (2002) do not find a significant gender coefficient in a Weibull survival model estimated using the 1993 and 1998 Vietnam Living Standards Survey (VLSS). Dao (2006) and Nguyen-Dinh and Feeny (1999), on the other hand, report higher mortality rates for men at all ages.

The present paper scrutinizes gender differences in Vietnam's child mortality rates using a sample with information on close to 30,000 births. We use econometric models that control for unobserved heterogeneity at the family and community level and allow for parametric flexibility. We estimate models separately for boys and girls to allow the effects of covariates to be different across genders.

Our empirical results show some remarkable gender patterns. Contrary to several other countries in the region, we find a $30 \%$ higher overall mortality rate for boys. The mortality rate of boys appears to be more sensitive to parents' education levels than the mortality rate of girls. A high education level of the father is particularly protective for boys. The rural-urban mortality difference in the raw data, which is particularly large for boys, can be fully explained by differences in observable characteristics of urban and rural households.

The paper proceeds as follows: Section 2 reviews developments in the Vietnamese society and health-care institutions that are relevant for understanding child mortality. Section 3 describes the data, while details of the econometric analysis are provided in Section 4. Section 5 presents the empirical results, and Section 6 concludes.

\section{The Vietnamese context}

After the reunification of the country in 1975, Vietnam witnessed a boom in the construction of health infrastructures and the training of health workers. By 1995, the Vietnam primary health-care network covered $93 \%$ of the communes around the country. As Table 1 shows, in 1995, infant mortality rate was around $32 \%$, much lower than in Bangladesh (83\%), Indonesia

\footnotetext{
${ }^{1}$ Nguyen-Dinh and Feeny (1999) use a logistic discrete-time model and data from the Vietnam Demographic and Health Survey 1988. O'Donnell et al. (2009) use quantile regression models and data from the 1993 and 1998 Vietnam Living Standards Surveys. Both papers focus on urban-rural differences, but do not consider gender effects.
} 


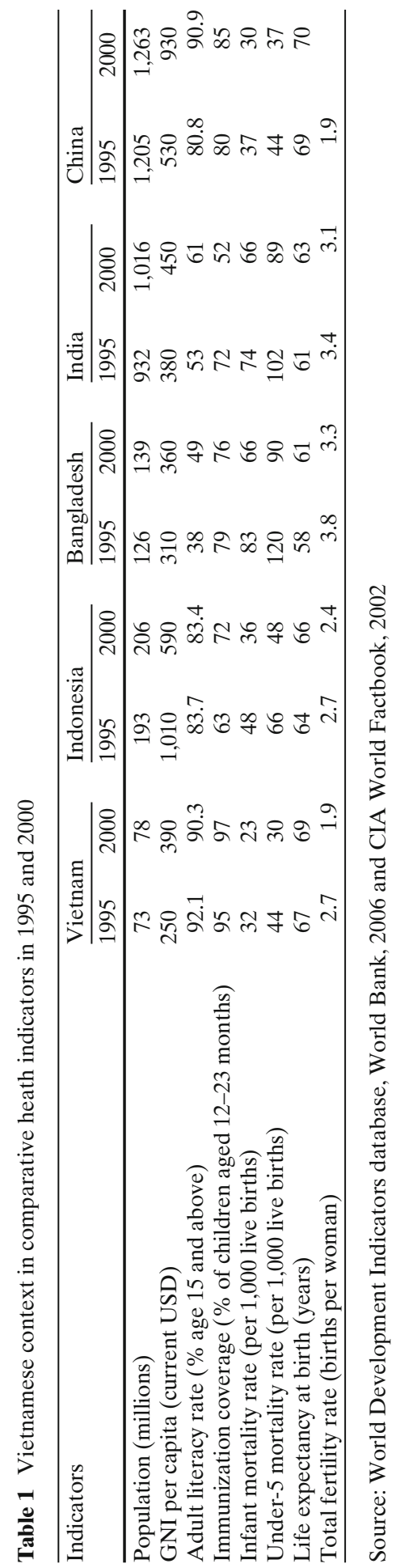


(48 \%o), and China (37 \%o). Other health indicators also compared favorably with other countries in Southeast Asia. With all health indicators showing strong improvements between 1995 and 2000 in all countries, Vietnam retained its top ranking.

Under the central planning economy, most national health services were provided free of charge or at highly subsidized prices. However, these circumstances changed profoundly upon the introduction of Doi Moi (reform) policy, which was introduced in 1986 and reinforced in 1989. While Doi Moi increased average living standards, it also increased inequality across social strata (see, e.g., Wagstaff and Nga (2002)). The early years of the transition to a market-oriented economy entailed a decline of health services in terms of health service delivery, equipment maintenance, and health workers' salaries. User fee charges for health care severely restricted access to health services for low-income households.

Facing the deterioration of the primary health-care system and the rapid population growth in the late 1980s, the Vietnamese government formulated strategies to renew the health-care system and family planning programs. Up to 2000, more than ten national health-care programs and projects were implemented, including the leprosy elimination program (1982), National Tuberculosis Control (1986), National Malaria Control (1991), the Expanded Program of Immunization (1993), acute respiratory infection control and

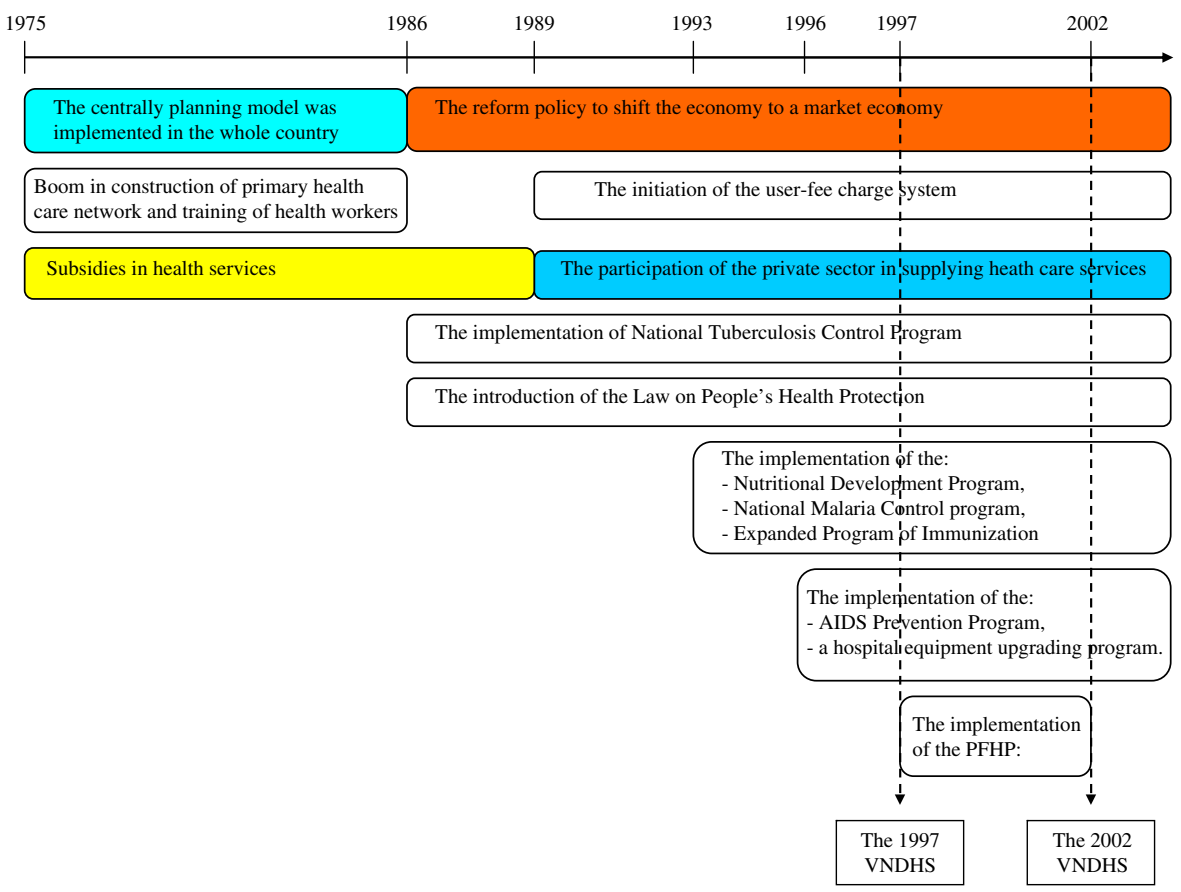

Fig. 1 Time line of relevant events during the transitional period 
the prevention of iodine deficiency (1996), and AIDS prevention, a hospital equipment upgrading program (1996). One of the effects of these programs was a strong increase in vaccination rates. The time line in Fig. 1 summarizes the main events and programs.

Goodkind (1995) mentions a study that suggests the existence of a boy preference in Vietnam, based on stated preferences. Any possible effect on the male/female birth ratio might have been reinforced by a birth control policy implemented in 1998 that calls for a maximum of "one or two children." In general, Vietnam has pursued a gender equality policy since 1945. Several health projects have targeted women only, for example, the Population and Family Health Project and the National Health Support Project (Pham 2009). These policies may have contributed to more gender equality and treatment of newborns that is independent of the sex of the newborn. As shown in the next section, the fraction of male births in our sample is only slightly larger than the natural male birth probability.

\section{Data and descriptive statistics}

Most of the studies on child mortality in Vietnam have used the 1988 Vietnam Demographic and Health Survey (VNDHS), the 1990 Vietnam Accessibility of Contraceptives Survey (with data on children born between 1983 and 1990), and the 1993 and 1998 VLSS.

Our empirical analysis is based on more recent versions of the VNDHS: 1997 and 2002. ${ }^{2}$ Both surveys are nationally representative household surveys. Data were collected at the level of individual ever-married women at reproductive ages (15-49 years old; 5,664 in 1997 and 5,665 in 2002), and at the community level. The main objectives of the surveys were to collect detailed information on fertility, family planning, and maternal and child health and survival indicators, as well as personal characteristics of the women such as their age, education, place of residence, working status, and their housing facilities. In VNDHSs, survey sites covered 41 provinces throughout the country. Although the repeated survey in 2002 returned to the same sample points (communities) as in the 1997 survey, the survey is not a panel at the level of individuals of households. However, it does constitute an (unbalanced) panel at the level of communities: we have data on 202 and 203 communities in 1997 and 2002, respectively, with 164 communities being surveyed in both years.

While information on socioeconomic factors refers to conditions at the survey time, information on birth history and child survival status is retrospective. Clearly, data derived from retrospective reporting could be subject to (time varying) measurement error. It should also be noted that our data

\footnotetext{
${ }^{2}$ The surveys were conducted by The National Committee for Population, Family and Children, NCFPFC (formerly NCFPFP) and the General Statistics Office, with technical assistance from ORC Macro, a professional service firm in Washington, DC, USA.
} 
are not a representative sample of the cohorts born between 1961 and 2002. The mothers with the earliest birth years in our data are those who were 49 in 1997, i.e., with birth years 1947 or 1948 . This implies that the children in our sample from birth year 1961 had very young mothers. This is likely to somewhat overestimate the mortality rates in the earlier years in Fig. 2. In our econometric analysis, this problem is less of a concern, as we will control for the mother's age at birth when explaining mortality. We will perform a robustness check by reestimating the models using children born to mothers from younger cohorts only.

From the complete birth history of sampled women, we have information on 29,900 live births to 10,734 mothers (there are 595 women who do not report any live births). The year of birth of the children spans from 1961 to 2002. During this relatively long time span, Vietnam has witnessed profound changes in terms of its political system, socioeconomic conditions, and health services. Table 2 shows the distribution of mothers by number of births and deaths. On average, a mother gives 2.79 live births. Almost half of the mothers have three or more children and about $7 \%$ have more than five. The 1,721 children who died account for $5.8 \%$ of the live births. The number of deaths is incurred by only $13 \%$ of the mothers. Only about $2.5 \%$ of mothers have experienced the loss of more than one child, but these deaths account for about $37 \%$ of total deaths. So there is clear evidence of clustering of deaths within households. This may be related to observed as well as unobserved mother-specific factors that induce a correlation between survival probabilities of the children of a given mother (sometimes referred to as "frailty").

Figure 2 graphs the developments of the overall child mortality rate in our data and shows a strong and persistent decline over the past decades. It also shows that mortality rates for boys have been higher in almost all years. This contrasts the pattern in several other countries in Asia, in particular India and China, in which girl mortality rates exceed boy mortality rates (see, for

Fig. 2 The time trend of child mortality rate. Source: VNDHS, 1997 and 2002

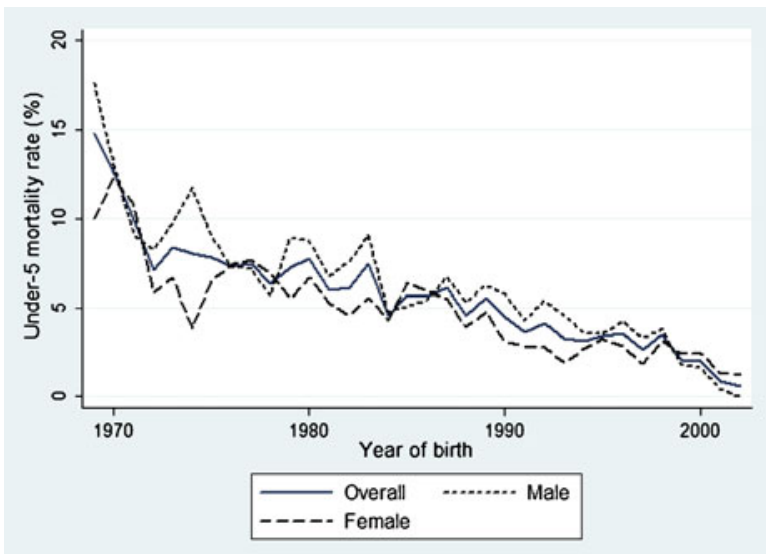

Source: VNDHS, 1997 and 2002 
Table 2 Distribution of mothers by number of births and deaths

\begin{tabular}{lrrrrrrrrr}
\hline Number of births & \multicolumn{9}{l}{ Number of deaths } \\
\cline { 2 - 11 } & \multicolumn{1}{l}{1} & \multicolumn{1}{l}{2} & \multicolumn{1}{l}{3} & 4 & 5 & 6 & 7 & Total \\
\hline 1 & 2,242 & 25 & 0 & 0 & 0 & 0 & 0 & 0 & 2,267 \\
2 & 3,397 & 105 & 4 & 0 & 0 & 0 & 0 & 0 & 3,506 \\
3 & 1,890 & 254 & 14 & 1 & 0 & 0 & 0 & 0 & 2,159 \\
4 & 1,019 & 272 & 32 & 2 & 0 & 0 & 0 & 0 & 1,325 \\
5 & 454 & 207 & 47 & 9 & 0 & 0 & 0 & 0 & 717 \\
6 & 225 & 117 & 46 & 8 & 0 & 1 & 0 & 0 & 397 \\
7 & 79 & 45 & 35 & 5 & 2 & 1 & 0 & 0 & 167 \\
8 & 38 & 39 & 20 & 6 & 2 & 0 & 0 & 1 & 106 \\
9 & 16 & 17 & 8 & 7 & 4 & 0 & 0 & 0 & 52 \\
10 & 8 & 6 & 5 & 4 & 3 & 1 & 0 & 0 & 27 \\
11 & 2 & 4 & 3 & 0 & 1 & 0 & 0 & 0 & 10 \\
12 & 0 & 0 & 0 & 0 & 0 & 0 & 1 & 0 & 1 \\
Total & 9,370 & 1,091 & 214 & 42 & 12 & 3 & 1 & 1 & 10,734 \\
\hline
\end{tabular}

example, van der Klaauw and Wang (2011) and www.who.org). Figure 3 plots the ratio of the rural-to-urban mortality rates, for boys and girls separately. The rural-to-urban ratios exceed 1 for both genders in virtually all years, in line with earlier findings. According to the present dataset, mortality rates are about $75 \%$ higher in rural compared to urban Vietnam. This difference is large. For example, Poel et al. (2009), who analyze a cross section of western sub-Saharan countries, find an average difference of $47 \%$. Second, the ruralurban differences for boys appear to be substantially larger than for girls, in some years even five to ten times larger.

Table 3 reports additional descriptive statistics, while Fig. 4 shows the kernel-smoothed baseline hazard curve over survival time. In general, children suffer from high risk of mortality early after birth, especially during the first month that represents more than $40 \%$ of total deaths. The hazard rate then

Fig. 3 Rural-to-urban child mortality rate ratios, by gender. Source: VNDHS, 1997 and 2002

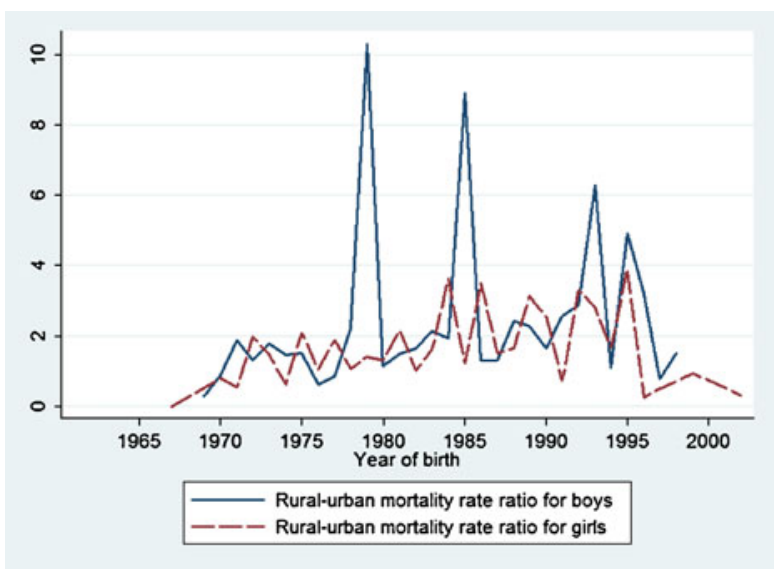

Source: VNDHS, 1997 and 2002 
Table 3 Definition and descriptive statistics of variables

\begin{tabular}{|c|c|c|c|c|c|}
\hline Variable & Observation & Mean & Std. dev & Min & $\operatorname{Max}$ \\
\hline Age at death or censor (in months) & 29,900 & 135.246 & 84.696 & 0.03 & 438 \\
\hline Child mortality & 29,900 & 0.058 & 0.233 & 0 & 1 \\
\hline \multicolumn{6}{|l|}{ Birth characteristics } \\
\hline First birth & 29,900 & 0.361 & 0.48 & 0 & 1 \\
\hline High birth order $(>4)$ & 29,900 & 0.098 & 0.297 & 0 & 1 \\
\hline Short preceding birth interval & 29,900 & 0.166 & 0.372 & 0 & 1 \\
\hline Child is male & 29,900 & 0.519 & 0.500 & 0 & 1 \\
\hline \multicolumn{6}{|l|}{ Fertility behavior } \\
\hline Age at first birth & 29,900 & 21.60 & 3.33 & 12 & 43 \\
\hline Age at birth is less than 18 & 29,900 & 0.021 & 0.144 & 0 & 1 \\
\hline Age at birth is greater than 35 & 29,900 & 0.042 & 0.200 & 0 & 1 \\
\hline \multicolumn{6}{|l|}{ Socioeconomic characteristics } \\
\hline Mother has no education & 29,900 & 0.082 & 0.274 & 0 & 1 \\
\hline Mother has primary or secondary education ${ }^{\mathrm{a}}$ & 29,900 & 0.899 & 0.301 & 0 & 1 \\
\hline Mother has high education & 29,900 & 0.019 & 0.136 & 0 & 1 \\
\hline Father has no education & 29,854 & 0.045 & 0.207 & 0 & 1 \\
\hline Father has primary or secondary education ${ }^{a}$ & 29,854 & 0.922 & 0.268 & 0 & 1 \\
\hline Father has high education & 29,854 & 0.033 & 0.179 & 0 & 1 \\
\hline Rural areas & 29,900 & 0.816 & 0.388 & 0 & 1 \\
\hline Kinh & 29,900 & 0.837 & 0.370 & 0 & 1 \\
\hline Lowest asset score group ${ }^{a}$ & 29,900 & 0.221 & 0.415 & 0 & 1 \\
\hline Second asset score group & 29,900 & 0.196 & 0.397 & 0 & 1 \\
\hline Middle asset score group & 29,900 & 0.197 & 0.398 & 0 & 1 \\
\hline Fourth asset score group & 29,900 & 0.200 & 0.400 & 0 & 1 \\
\hline Highest asset score group & 29,900 & 0.187 & 0.390 & 0 & 1 \\
\hline \multicolumn{6}{|l|}{ Regions } \\
\hline Northern uplands & 29,900 & 0.197 & 0.398 & 0 & 1 \\
\hline Red River Delta & 29,900 & 0.171 & 0.376 & 0 & 1 \\
\hline Northern central & 29,900 & 0.152 & 0.359 & 0 & 1 \\
\hline Central coast & 29,900 & 0.106 & 0.308 & 0 & 1 \\
\hline Central highlands & 29,900 & 0.042 & 0.201 & 0 & 1 \\
\hline Southeast & 29,900 & 0.105 & 0.306 & 0 & 1 \\
\hline Mekong River Delta ${ }^{\mathrm{a}}$ & 29,900 & 0.228 & 0.419 & 0 & 1 \\
\hline \multicolumn{6}{|l|}{ Calendar time trend } \\
\hline Born before $1976^{\mathrm{a}}$ & 29,900 & 0.048 & 0.214 & 0 & 1 \\
\hline Born between 1976 and 1986 & 29,900 & 0.382 & 0.486 & 0 & 1 \\
\hline Born between 1986 and 1989 & 29,900 & 0.146 & 0.353 & 0 & 1 \\
\hline Born between 1989 and 1993 & 29,900 & 0.200 & 0.400 & 0 & 1 \\
\hline Born between 1993 and 1996 & 29,900 & 0.122 & 0.328 & 0 & 1 \\
\hline Born after 1996 & 29,900 & 0.101 & 0.302 & 0 & 1 \\
\hline
\end{tabular}

${ }^{\text {a Reference group }}$

declines sharply over time and then becomes small and more or less constant after the fifth year.

\section{Empirical methods}

Mosley and Chen (1984) proposed an analytical framework for examining determinants of child mortality in developing countries that has been used widely. Their framework postulates that the effects of socioeconomic factors 
Fig. 4 Variation of hazard rate over survival time

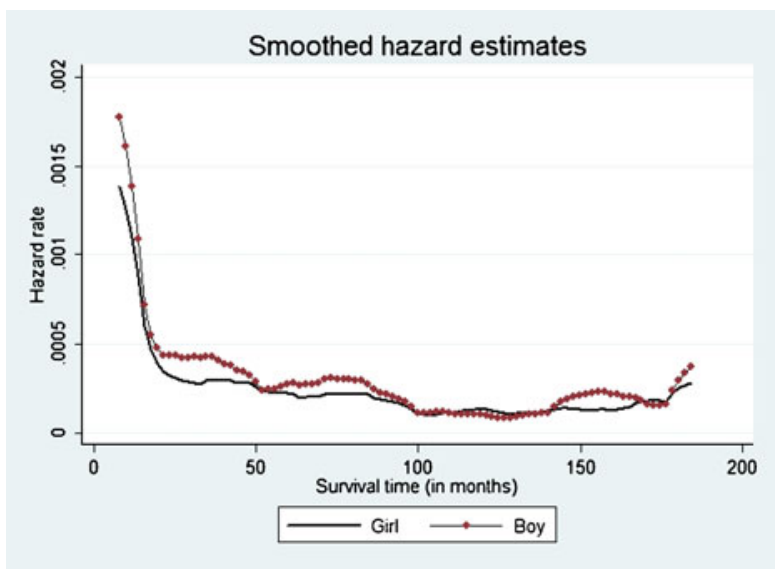

on child mortality operate through a common set of biological mechanisms or proximate determinants which are categorized into five groups: (1) maternal factors including fertility behaviors, (2) environmental health conditions, (3) nutritional status, (4) injury, and (5) personal illness control. Although the framework is often referenced, only a few studies control for all the proximate determinants due to the limitations of the data. Previous studies examine the effect of fertility-related behavior such as birth interval and breastfeeding duration (Hobcraft et al. 1983; Palloni and Millman 1986; Boerma and Bicego 1992; Nath et al. 1994), explore the causal relationship between socioeconomic factors and child mortality (Trussell and Hammerslough 1983; Hobcraft et al. 1985; Guilkey and Riphahn 1998), or do both (van der Klaauw and Wang 2011).

The explanatory variables in the present study are motivated by both the Mosley-Chen framework and data availability. We distinguish between five types of explanatory variables: birth characteristics, fertility behavior, socioeconomic characteristics, regional variables, and time effects. Households' asset score acts as a proxy for household income and wealth and is defined as the ownership of a number of durable goods such as a television, car, motorcycle, toilet facilities, etc. Each asset is assigned a weight or factor score generated through principal components analysis (Rutstein and Johnson 2004). These scores are then used to create the break points that define wealth quintiles.

Our key econometric tool for investigating the determinants of child mortality is a proportional hazard model with a semiparametric piecewise-constant hazard rate for the intervals $0-1,1-6,6-12,12-24,24-60$, and > 60 months (cf. Greene (2003)). ${ }^{3}$

\footnotetext{
${ }^{3}$ For children who are younger than 1 month, we take age equal to half a month. The results are very similar to those from a model that uses $\operatorname{Pr}(0<t<1)$. For children who die within 1 month after birth, the original dataset gives the time at death in days which is converted into months by dividing the time by 30 . For living children, the variable survival time represents (censored) age in months at the time of the survey. For children who died before the survey, the (uncensored) survival time is defined as age at the time of death.
} 
Children born to the same mothers are likely to share unobserved motherspecific biological and genetic factors and unobserved household socioeconomic conditions. We therefore allow for a potential correlation between the hazards of sibling by including a mother-specific random effect (frailty) parameter. The hazard function for child $i$ of mother $m$ with $I_{m}$ children is specified as

$$
h\left(t_{i} \mid v_{m}\right)=v_{m} h_{0}(t) \exp \left(\beta^{\prime} \mathbf{X}_{\mathbf{i}}\right), \quad i=1, \ldots, I_{m} .
$$

Following Vaupel et al. (1979), we assume $v_{m}$ to follow a gamma distribution with unit mean and a finite variance $\sigma^{2}$. Abbring and van den Berg (2007) show that in a large class of hazard models with proportional unobserved heterogeneity, the distribution of unobserved heterogeneity converges to a gamma distribution. Gutierrez (2002) provides details on estimation. The null hypothesis that $v=0$ can be tested using a boundary-value likelihood-ratio test based on a mixture of $\bar{\chi}_{01}^{2}$ distributions (see Gutierrez et al. (2001)). Clayton (1978) and Guo and Rodriguez (1992) noted an interesting interpretation of $\sigma^{2}$. The model implies that the ratio of the hazard of a child at $t_{1}$ given a number of child deaths in the family, to the hypothetical hazard of the same child given no deaths in the family, is given by

$$
\frac{h_{i}\left(t_{1} \mid t_{2}, \ldots, t_{I_{m}} ; \delta_{2}, \ldots, \delta_{I_{m}}\right)}{h_{i}\left(t_{1} \mid t_{2}, \ldots, t_{I_{m}} ; 0, \ldots, 0\right)}=1+\sigma^{2} \sum_{j=1}^{I_{m}} \delta_{j}
$$

where $\delta_{j}$ equals 1 if child $j$ died at $t_{j}$ and 0 , otherwise. Hence, the hazard rate of dying increases by $\sigma^{2}$ multiplied by the number of deaths. This expression provides a measure of the size of the mother-specific unobserved effects. ${ }^{4}$

\section{Estimation results}

Table 4 presents estimation results for three versions of the hazard rate model, without unobserved heterogeneity (columns 1 and 2), with unobserved heterogeneity (columns 3 and 4), and with unobserved heterogeneity and community-specific fixed effects (columns 5 and 6). Note that the estimated coefficients on the covariates hardly vary across the three versions of the model.

Gender The effect of gender-our primary interest—is large and highly significant. The coefficients imply that for boys, the probability of dying before a particular age is $30 \%$ larger than for girls. While excess girl mortality has been found for a number of Asian countries, in particular India and China, excess male mortality rates (at all ages, including the youngest) is found in almost any

\footnotetext{
${ }^{4}$ van der Klaauw and Wang (2011) also allow for child-specific frailty, in addition to frailty at the family level. Their empirical results do not show any significant and substantial child-specific frailty.
} 
Table 4 The piecewise constant exponential model

\begin{tabular}{|c|c|c|c|c|c|c|}
\hline \multirow[t]{2}{*}{ Variable } & \multicolumn{2}{|c|}{ No-frailty model } & \multicolumn{2}{|c|}{ Frailty model } & \multicolumn{2}{|c|}{ Frailty model with CFE } \\
\hline & $\overline{\text { Coefficient }}$ & s.e. & $\overline{\text { Coefficient }}$ & s.e. & Coefficient & s.e. \\
\hline \multicolumn{7}{|l|}{ Survival time intervals } \\
\hline Month 0-1 & $5.653^{* * *}$ & 0.074 & $5.620^{* * *}$ & 0.074 & $5.475^{* * *}$ & 0.074 \\
\hline Month 1-6 & $2.753^{* * *}$ & 0.101 & $2.728^{* * *}$ & 0.102 & $2.727^{* * *}$ & 0.102 \\
\hline Month 6-12 & $2.200^{* * *}$ & 0.107 & $2.178^{* * *}$ & 0.107 & $2.177^{* * *}$ & 0.107 \\
\hline Month 12-24 & $1.502^{* * *}$ & 0.108 & $1.485^{* * *}$ & 0.108 & $1.485^{* * *}$ & 0.108 \\
\hline Month 24-60 & $1.232^{* * * *}$ & 0.087 & $1.220^{* * *}$ & 0.087 & $1.220^{* * *}$ & 0.087 \\
\hline \multicolumn{7}{|l|}{ Birth characteristics } \\
\hline First birth & $0.300^{* * *}$ & 0.061 & $0.308^{* * *}$ & 0.062 & $0.298^{* * *}$ & 0.062 \\
\hline High birth order $(>4)$ & $0.180^{* *}$ & 0.083 & 0.101 & 0.086 & 0.097 & 0.086 \\
\hline Short preceding birth interval & $0.624^{* * *}$ & 0.062 & $0.583^{* * *}$ & 0.064 & $0.577^{* * *}$ & 0.064 \\
\hline Child is male & $0.260^{* * *}$ & 0.049 & $0.266^{* * *}$ & 0.050 & $0.263^{* * *}$ & 0.050 \\
\hline \multicolumn{7}{|l|}{ Fertility behavior } \\
\hline Age at first birth & $-0.042^{* * *}$ & 0.016 & $-0.045^{* * *}$ & 0.017 & $-0.027^{* *}$ & 0.009 \\
\hline Age at birth is less than 18 & $0.323^{* *}$ & 0.128 & $0.346^{* * *}$ & 0.132 & $0.389^{* * *}$ & 0.132 \\
\hline Age at birth is greater than 35 & 0.233 & 0.144 & $0.272^{*}$ & 0.147 & $0.284^{*}$ & 0.147 \\
\hline \multicolumn{7}{|l|}{ Socioeconomic characteristics } \\
\hline Mother has no education & $0.220^{* * *}$ & 0.082 & $0.244^{* * *}$ & 0.094 & $0.313^{* * *}$ & 0.096 \\
\hline Mother has high education & -0.277 & 0.323 & -0.283 & 0.330 & -0.280 & 0.331 \\
\hline Father has no education & $0.183^{*}$ & 0.102 & 0.155 & 0.118 & $0.225^{*}$ & 0.118 \\
\hline Father has high education & $-0.471^{* *}$ & 0.230 & $-0.462^{*}$ & 0.237 & $-0.480^{* *}$ & 0.238 \\
\hline Rural areas & 0.096 & 0.090 & 0.120 & 0.095 & - & - \\
\hline Kinh & $-0.251^{* * *}$ & 0.073 & $-0.247^{* * *}$ & 0.080 & $-0.241^{\text {** }}$ & 0.101 \\
\hline Second asset score group & $-0.129^{*}$ & 0.072 & -0.123 & 0.080 & $-0.140^{*}$ & 0.082 \\
\hline Middle asset score group & $-0.373^{* * *}$ & 0.082 & $-0.380^{* * *}$ & 0.090 & $-0.404^{* * *}$ & 0.094 \\
\hline Fourth asset score group & $-0.350^{* * *}$ & 0.086 & $-0.347^{* * *}$ & 0.093 & $-0.407^{* * *}$ & 0.098 \\
\hline Highest asset score group & $-0.572^{* * *}$ & 0.113 & $-0.566^{* * *}$ & 0.120 & $-0.669^{* * *}$ & 0.125 \\
\hline \multicolumn{7}{|l|}{ Regions } \\
\hline Northern uplands & -0.066 & 0.080 & -0.054 & 0.086 & - & - \\
\hline Red River Delta & -0.134 & 0.091 & -0.155 & 0.097 & - & - \\
\hline Northern central & 0.037 & 0.081 & 0.028 & 0.088 & - & - \\
\hline Central coast & $0.151^{*}$ & 0.089 & 0.119 & 0.098 & - & - \\
\hline Central highlands & -0.062 & 0.133 & -0.066 & 0.146 & - & - \\
\hline Southeast & -0.118 & 0.106 & -0.124 & 0.113 & - & - \\
\hline \multicolumn{7}{|l|}{ Calendar time trend } \\
\hline Born between 1976 and 1986 & $-0.183^{* *}$ & 0.089 & $-0.178^{*}$ & 0.094 & $-0.182^{*}$ & 0.094 \\
\hline Born between 1986 and 1989 & $-0.298^{* * *}$ & 0.105 & $-0.308^{* * *}$ & 0.110 & $-0.311^{* * *}$ & 0.110 \\
\hline Born between 1989 and 1993 & $-0.676^{* * *}$ & 0.107 & $-0.679^{* * *}$ & 0.112 & $-0.686^{* * *}$ & 0.112 \\
\hline Born between 1993 and 1996 & $-0.724^{* * *}$ & 0.124 & $-0.733^{* * *}$ & 0.129 & $-0.731^{* * *}$ & 0.129 \\
\hline Born after 1996 & $-1.089^{* * *}$ & 0.153 & $-1.096^{* * *}$ & 0.158 & $-1.085^{* * *}$ & 0.158 \\
\hline Constant & $-8.436^{* * *}$ & 0.231 & $-8.379^{* * *}$ & 0.248 & $-7.442^{* * *}$ & 0.534 \\
\hline$\sigma^{2}$ & & & $0.540^{* * *}$ & 0.093 & $0.335^{* * *}$ & 0.079 \\
\hline $\operatorname{Pr}>\bar{\chi}_{01}^{2}$ & & & 0.000 & & 0.000 & \\
\hline Number of observation & 165,139 & & 165,139 & & 165,139 & \\
\hline Number of children & 29,854 & & 29,854 & & 29,854 & \\
\hline Log-likelihood & $-10,482$ & & $-10,454$ & & $-10,315$ & \\
\hline AIC & 21,034 & & 20,980 & & 21,095 & \\
\hline $\operatorname{Pr}>\chi^{2}$ & 0.0000 & & 0.0000 & & 0.0000 & \\
\hline
\end{tabular}

s.e. standard error, $C F E$ community fixed effects

$* p<0.1 ; * * p<0.05 ; * * * p<0.01$ (level of significance) 
society around the globe (http://www.who.int/healthinfo/morttables/en). The estimated gender coefficient in the Weibull model estimated by Wagstaff and Nga (2002) using the 1993 and 1998 VLSS also suggests excess boy mortality, but their coefficient is insignificant. This could be related to their smaller sample size or to the fact that they use older data (and older cohorts). Dao (2006) and Nguyen-Dinh and Feeny (1999), on the other hand, report higher mortality rates for men at all ages, as reported here. A similar result for another country in the Asian Pacific region, the Philippines, is reported by Guilkey and Riphahn (1998).

A potential explanation for the higher levels of boy mortality is related to parental gender preferences. In our sample, the sex ratio (male/female) at birth (SRB) is 106.2, only slightly larger than the natural SRB of 105. For third and higher parities, the SRB is 109.5 . Both differences are significant at the $5 \%$ level, but not at the $1 \%$ level. Thus, we find some evidence that the SRB is higher than the natural sex ratio at birth but to a much lesser extent than in other Asian countries. ${ }^{5}$ Similar results are reported in Bélanger et al. (2003). Pham (2009) finds shorter breast-feeding duration for boys. These findings suggest that any preferential treatment of male infants in Vietnam was limited or absent. As a consequence, the gender mortality pattern is closer to the usual pattern found around the globe. ${ }^{6}$ At the end of this section, we investigate this gender difference in more detail. We now first discuss the effects of the other coefficients.

Sibling correlations A mother-specific random effect reflects a correlation between the risk of death among siblings and family death clustering. As expected, the estimate of $\sigma^{2}$ in the model with community fixed effects is lower than in the model without. Yet, the estimate of $\sigma^{2}$ in the model with community fixed effects is still substantial. It implies that each death of a child in a family increases the mortality risk of the index child by $34 \%$, other things equal. This large effect may come from various unobserved factors like illness control behavior, parental competence, household economic status, and genetic factors. The estimate of $\sigma^{2}$ varies widely across studies. While Guo (1993) estimates 0.14, using the Institute for Nutrition in Central America and Panama Survey data, Omariba et al. (2007) using the 1998 Kenya Demographic and Health Survey find a value of about $0.98 .^{7}$

\footnotetext{
${ }^{5}$ For example, the SRB is China is estimated to be at 1.20 (http://esa.un.org/unpd/wpp/SortingTables/tab-sorting_fertility.htm).

${ }^{6}$ The sex ratio at birth in Vietnam has increased after our data were collected. This happened later than in other Asian countries and is likely to be related to supply factors (prebirth sex assessment, abortion) rather than an increasing preference for sons (see UNFPA (2009) and Guilmoto et al. (2009)). Chamarbagwala (2011) argues that a balanced gender composition may be important to parents in India, causing selective survival bias.

${ }^{7}$ From Table 2, it is evident that there are only a few families with a very high mortality. If we exclude all families with five or more deaths, the estimated $\sigma^{2}$ in the frailty model without community fixed effects drops from 0.540 to 0.465 , while all other estimates remain virtually unchanged.
} 
Table 5 Proportional effect of calendar time and survival time on hazard rate

\begin{tabular}{lrlr}
\hline Calendar time & \multicolumn{3}{l}{ Survival time } \\
\hline Child born before 1976 & 1 & Child aged within 1 month & 18.021 \\
Born between 1976 and 1986 & 0.837 & Aged between 1 and 6 months & 1 \\
Born between 1986 and 1989 & 0.735 & Aged between 6 and 12 months & 0.577 \\
Born between 1989 and 1993 & 0.507 & Aged between 12 and 24 months & 0.289 \\
Born between 1993 and 1996 & 0.480 & Aged between 24 and 60 months & 0.221 \\
Born after 1996 & 0.334 & Aged greater than 60 months & 0.065 \\
\hline
\end{tabular}

The community fixed effects are jointly highly significant $(p<0.1)$, but their inclusion has little effect on the other coefficients. Since the model without community fixed effects also allows to estimate the seven coefficients of the regional variables, we focus on this version of the model in the sequel.

Time effects Table 5 presents the proportional effect of the calendar and survival time on the hazard rate. The result in the first column, first row reflects the raw data, in which about $40 \%$ of deaths occur during the first months after birth (cf. Lawn et al. (2005)). Figure 2 already showed a strong declining time trend of mortality as a function of calendar time. The estimated coefficients on calendar time in Table 4 indicate that this strong decline remains after controlling for observed explanatory variables. This indicates a substantial role for unobserved factors that are changing over time and not included in the model, like household income, technical advances in health-care services, and learning effects. While it is tempting to link the time effect to the policy changes reflected in Fig. 1, we of course cannot claim to have found any causal effects of policies. ${ }^{8}$

Birth order and fertility behavior Birth order has a strong effect on child mortality. Estimated coefficients of the first-order birth and high-order birth variables imply a U-shaped effect of birth order on child mortality, although high-order birth is not statistically significant in the model versions with frailty. The risk for the first birth is about $33 \%$ higher than that for the other order births. This finding is similar to those found in previous studies by Swenson et al. (1993, 1995) and Nguyen-Dinh and Feeny (1999), largely based on the 1988 Vietnam Demographic and Health Survey. The high risk for the first births is caused by generally more difficult deliveries at first births (dystocia) and the lack of experience with childbearing and childrearing. The lower risk for the later births may result from learning effects among mothers. The increased risk for higher order births might be related to maternal depletion and sibling competition with resources. The significance of high birth order in

\footnotetext{
${ }^{8}$ In an earlier stage of this project, we attempted to link the results more closely to health policy events, in particular the Population and Family Health Project (PFHP), but were unable to establish causal effects. One problem was that about one-third of the PFHP resources appeared to be spent on nonproject (control) provinces. Another problem was that several other programs were implemented simultaneously, with insufficient information on timing and location.
} 
the model without frailty and insignificance in the model with frailty indicates that higher birth orders are more likely to occur in poor families with limited resources (not captured by covariates) (see Horton (1988)).

Mother's age and birth intervals The literature on the effects of mother's age on child mortality shows mixed results. Swenson et al. (1993) and Nguyen-Dinh and Feeny (1999), using a smaller sample for Vietnam (one-fifth of the current sample size) for the birth years 1979-1988, find that mother's age at birth does not contribute to increased mortality risk of the children. However, others find significant effects for other Asian countries such as India (Nath et al. 1994) and Sri Lanka (Trussell and Hammerslough 1983). The present results imply that a mother under 18 faces a more than $30 \%$ higher risk of death of her child. A 1-year increase in the mother's age at first birth decreases the risk of death of her child by about $4 \%$. Similar to Makepeace and Pal (2006), we find that the risk for the first birth is significantly reduced with higher age at first birth.

A short preceding birth interval is an important determinant of child mortality. The estimated coefficient is statistically significant and positive, and substantial in magnitude. Other things equal, the mortality risk for a birth with less than 24-month birth spacing is as much as $75 \%$ higher than that for other nonfirst births. ${ }^{9}$ The effect of short birth interval is likely to be related to maternal depletion and sibling competition. While the results are consistent with most of the existing literature, they differ from the findings in previous studies on Vietnam that document no significant relationship between child spacing and mortality (Swenson et al. 1993 and Nguyen-Dinh and Feeny 1999). The difference might be related to the profound changes in the socioeconomic context during the transition in Vietnam initiated from the early 1990s. The shift from the centrally planning economy to the market economy increased working pressures on women and reduced subsidies related to childbearing and childrearing. These changes might have contributed to maternal depletion and sibling competition.

Socioeconomic factors It has been well documented that better parental education is associated with lower child mortality risk due to better feeding practices, illness controls, and child-care (see Caldwell and McDonald (1982), Cochrane et al. (1982), Hobcraft et al. (1984), and Majumder and Islam (1993)). Our findings confirm this for Vietnam. The estimated coefficients are positive for illiterate parents and negative for highly educated parents, with two of the four coefficients being (highly) significant. Illiteracy of the mother harms more than illiteracy of the father, while a high paternal education reduces risk more than a high maternal education. The effects are large. For example, high parental education reduces mortality risk by about $40 \%$. Our

\footnotetext{
${ }^{9}$ It should be noted that in the absence of a simultaneous model that explains both child mortality and birth spacing, the effect might be biased. The papers by Makepeace and Pal (2008) and Bhalotra and van Soest (2008), both based on data from India, are unequivocal on the direction and magnitude of the bias.
} 
estimation results somewhat differ from the findings in previous studies on Vietnam. Swenson et al. (1993, 1995), Anh (1995), and Nguyen-Dinh and Feeny (1999) find that basic education plays a dominant role in reducing child mortality rate but that the extra effect of more education is small. At the end of Section 5, we will examine gender patterns in the role of parental education in more detail.

The household asset score is an important predictor of child mortality. For children in the lowest asset score quintile, the mortality risk is more than twice as large as in the highest quintile.

Ethnicity has a significant effect on child mortality risk. The probability that a Kinh child dies is about $20 \%$ smaller than the probability for a child from an ethnic minority. Most of the ethnic minorities live in rural, remote, and disadvantaged areas and face less favorable economic conditions than the Kinh peers, even conditional on residence, education, and other covariates.

Regional effects The raw data showed that children living in rural areas face a $77 \%$ higher mortality risk compared to urban areas. However, the urbanrural dummy as well as the seven regional variables in the model are all insignificant. This indicates that the urban-rural gap is fully attributable to differences in observable characteristics, in particular parental education and household asset score.

\subsection{A closer look at gender patterns}

To better understand the gender difference in child mortality, we have estimated the model separately for boys and girls (see Table 6). We present the no-frailty results as the coefficients on the explanatory variables are very similar between the three versions of the model. For convenience, we repeat the results for the total sample in Table 4. A likelihood ratio test shows that the sets of estimates obtained for the two genders are statistically different $(p<0.1)$.

Notably, different effects for boys and girls are found for education. First, a low education level of the mother increases mortality risk, but the effect is significant for boys only. Conversely, a low education level of the father increases mortality risk as well, but the effect is significant for girls only. The pattern becomes even more subtle when we consider the effects of a high parental education. The coefficient of the mother having a high education is negative for girls but insignificant. The coefficients on the father having a high education is negative for both boys and girls but significant for boys only. The latter effect is also very large, a reduction by $50 \%$. Summarizing the eight coefficients representing the various gender-specific interactions, we conclude that boy mortality is more sensitive to parents' education levels than girls mortality. In addition, a high education level of the father is especially protective for boys. We also find that a high birth order has a large positive effect on mortality for boys, but not for girls. On the other hand, having a 
Table 6 Estimation results by gender

\begin{tabular}{|c|c|c|c|c|c|c|}
\hline \multirow[t]{2}{*}{ Variable } & \multicolumn{2}{|l|}{ Total sample } & \multicolumn{2}{|l|}{ Boys } & \multicolumn{2}{|l|}{ Girls } \\
\hline & Coefficient & s.e. & Coefficient & s.e. & Coefficient & s.e. \\
\hline \multicolumn{7}{|l|}{ Survival time intervals } \\
\hline Month 0-1 & $5.653^{* * *}$ & 0.074 & $5.724^{* * *}$ & 0.098 & $5.554^{* * *}$ & 0.111 \\
\hline Month 1-6 & $2.753^{* * *}$ & 0.101 & $2.780^{* * *}$ & 0.135 & $2.721^{* * *}$ & 0.154 \\
\hline Month 6-12 & $2.200^{* * *}$ & 0.107 & $2.100^{* * *}$ & 0.148 & $2.316^{* * *}$ & 0.155 \\
\hline Month 12-24 & $1.502^{* * *}$ & 0.108 & $1.502^{* * *}$ & 0.144 & $1.505^{* * *}$ & 0.162 \\
\hline Month 24-60 & $1.232^{* * *}$ & 0.087 & $1.275^{* * *}$ & 0.115 & $1.178^{* * *}$ & 0.132 \\
\hline \multicolumn{7}{|l|}{ Birth characteristics } \\
\hline First birth & $0.300^{* * *}$ & 0.061 & $0.276^{* * *}$ & 0.081 & $0.329^{* * *}$ & 0.095 \\
\hline High birth order $(>4)$ & $0.180^{* *}$ & 0.083 & $0.297^{* *}$ & 0.105 & 0.037 & 0.134 \\
\hline Short preceding birth interval & $0.624^{* * *}$ & 0.062 & $0.571^{* * *}$ & 0.082 & $0.690^{* * *}$ & 0.095 \\
\hline Child is male & $0.260^{* * *}$ & 0.049 & - & - & - & - \\
\hline \multicolumn{7}{|l|}{ Fertility behavior } \\
\hline Age at first birth & $-0.042^{* * *}$ & 0.016 & $-0.038^{*}$ & 0.021 & $-0.044^{*}$ & 0.024 \\
\hline Age at birth is less than 18 & $0.323^{* *}$ & 0.128 & $0.304^{*}$ & 0.170 & $0.336^{*}$ & 0.196 \\
\hline Age at birth is greater than 35 & 0.233 & 0.144 & -0.043 & 0.203 & $0.542^{* * *}$ & 0.206 \\
\hline \multicolumn{7}{|l|}{ Socioeconomic characteristics } \\
\hline Mother has no education & $0.220^{* * *}$ & 0.082 & $0.241^{* *}$ & 0.107 & 0.194 & 0.129 \\
\hline Mother has high education & -0.277 & 0.323 & 0.117 & 0.384 & -0.921 & 0.603 \\
\hline Father has no education & $0.183^{*}$ & 0.102 & 0.056 & 0.140 & $0.334^{* *}$ & 0.151 \\
\hline Father has high education & $-0.471^{* *}$ & 0.230 & $-0.712^{* *}$ & 0.329 & -0.205 & 0.321 \\
\hline Rural areas & 0.096 & 0.090 & 0.185 & 0.121 & -0.017 & 0.134 \\
\hline Kinh & $-0.251^{* * *}$ & 0.073 & $-0.254^{* * *}$ & 0.096 & $-0.247^{* *}$ & 0.113 \\
\hline Second asset score group & $-0.129^{*}$ & 0.072 & -0.150 & 0.095 & -0.098 & 0.112 \\
\hline Middle asset score group & $-0.373^{* * *}$ & 0.082 & $-0.309^{* * *}$ & 0.106 & $-0.468^{* * *}$ & 0.131 \\
\hline Fourth asset score group & $-0.350^{* * *}$ & 0.086 & $-0.408^{* * *}$ & 0.115 & $-0.267^{* *}$ & 0.132 \\
\hline Highest asset score group & $-0.572^{* * *}$ & 0.113 & $-0.572^{* * *}$ & 0.150 & $-0.552^{* * *}$ & 0.172 \\
\hline \multicolumn{7}{|l|}{ Regions } \\
\hline Northern uplands & -0.066 & 0.080 & -0.090 & 0.106 & -0.024 & 0.122 \\
\hline Red River Delta & -0.134 & 0.091 & -0.14 & 0.121 & -0.132 & 0.139 \\
\hline Northern central & 0.037 & 0.081 & 0.059 & 0.106 & 0.018 & 0.125 \\
\hline Central coast & $0.151^{*}$ & 0.089 & 0.151 & 0.117 & 0.152 & 0.136 \\
\hline Central highlands & -0.062 & 0.133 & 0.100 & 0.165 & -0.330 & 0.228 \\
\hline Southeast & -0.118 & 0.106 & -0.059 & 0.139 & -0.211 & 0.163 \\
\hline \multicolumn{7}{|l|}{ Calendar time trend } \\
\hline Born between 1976 and 1986 & $-0.183^{* *}$ & 0.089 & $-0.280^{* *}$ & 0.116 & -0.056 & 0.141 \\
\hline Born between 1986 and 1989 & $-0.298^{* * *}$ & 0.105 & $-0.321^{* *}$ & 0.135 & $-0.270^{*}$ & 0.166 \\
\hline Born between 1989 and 1993 & $-0.676^{* * *}$ & 0.107 & $-0.580^{* * *}$ & 0.135 & $-0.847^{* * *}$ & 0.175 \\
\hline Born between 1993 and 1996 & $-0.724^{* * *}$ & 0.124 & $-0.741^{* * *}$ & 0.160 & $-0.705^{* * *}$ & 0.196 \\
\hline Born after 1996 & $-1.089^{* * *}$ & 0.153 & $-1.240^{* * *}$ & 0.209 & $-0.883^{* * *}$ & 0.230 \\
\hline Constant & $-8.436^{* * *}$ & 0.231 & $-8.157^{* * *}$ & 0.304 & $-8.470^{* * *}$ & 0.352 \\
\hline Number of observation & 165,139 & & 85,339 & & 79,800 & \\
\hline Number of children & 29,854 & & 15,490 & & 14,364 & \\
\hline Log-likelihood & $-10,545$ & & $-5,982$ & & $-4,482$ & \\
\hline AIC & 21,146 & & 12,031 & & 9,032 & \\
\hline $\operatorname{Pr}>\chi^{2}$ & 0.0000 & & 0.0000 & & 0.0000 & \\
\hline
\end{tabular}

$* p<0.1 ; * * p<0.05 ; * * * p<0.01$ (level of significance)

mother aged 35 or above at birth has a large positive effect on girl mortality, but not on boy mortality.

One can think of several explanations for these patterns. The more harmful effect of a mother's illiteracy for boys could be related to a stronger bond be- 
tween mothers and daughters versus mothers and sons. Some evidence of the bonding difference is suggested by the shorter breast-feeding duration for boys (see Pham (2009)). Education might induce mothers towards more equality in treating daughters and sons. Huong et al. (2006) report on the basis of verbal autopsy information that traffic accidents and drowning are leading causes of death of male children (and adults). Fathers' education can contribute to awareness and vigilance regarding these risks and more effectively so when fathers have stronger bonds with sons or are more authoritative than mothers. Finally, several studies report that boys are more susceptible to diarrhea and respiratory infection (see, e.g., Adair et al. (1993), Cebu Study Team (1992), and Pham (2009)). These diseases are sometimes a precursor to death. ${ }^{10}$ As noted by Merli (1998), the larger boy mortality could have resulted from warrelated violence. Again, education is likely to mitigate the effects of such detrimental circumstances.

As a robustness check, we have reestimated the models using more recent cohorts only, dropping from the sample children born before 1986. The estimated coefficients only change slightly, suggesting that possible biases resulting from recollection error and sample nonrepresentitiveness are small.

\section{Conclusion}

Scholars in various disciplines have documented the relatively low child mortality levels in Vietnam, as well as its strong decrease during the past decades. Large urban-rural differences have been reported as well.

Focusing on gender differences in mortality patterns in the raw data, we find that Vietnam conforms to the usual pattern found almost anywhere else in the world, contrary to several other Asian countries: excess boy mortality. This is found particularly in rural Vietnam.

Various explanations can be put forward for this difference in mortality rates at the aggregate level. In other Asian countries, boy preferenceevidenced by a higher than natural male/female birth ratio-has been mentioned to explain lower boy mortality. Our sample shows a somewhat higher than natural male/female birth ratio but to a much lesser extent than in other Asian countries. This suggests that strong preferential treatment of male infants, with the associated lower boy mortality, does not apply to Vietnam.

Further explanations for excess boy mortality are that-especially in rural districts-boys are more involved in risky behaviors that result in accidents

\footnotetext{
${ }^{10}$ The Vietnam DHS data in principle also allow for an analysis of morbidity. A difficulty—besides a smaller sample size-is a lack of instrumental variables to control for the endogeneity of health inputs, like vaccinations and the use of contraceptives. As a consequence, questions about the effectiveness of programs like PFHP remain difficult to answer. The best approach with respect to future programs is to have them preceded by small-scale pilots in which program communities or provinces are randomly selected. Such a procedure allows for a sound scientific evaluation of program effectiveness and thus for an equitable allocation of resources such that the living conditions of the most vulnerable children are improved.
} 
such as drowning and that boys are more likely to be involved in traffic accidents and war-related violence. An additional explanation for the higher mortality rate of boys at the aggregate level is implied in our estimation results. Mortality rates for boys from higher birth orders are significantly higher (Table 6, columns 3 and 4). This effect was not found for girls (Table 6, columns 5 and 6). Given that the male/female ratio at birth is larger at higher parities, this effect increases the average aggregate mortality rate for boys.

We examined mortality patterns and gender differences at an individual level that have not been the focus of research in the literature so far. The mortality rate of boys appears to be more sensitive to parents' education levels than the mortality rate of girls. A high education level of the father is particularly protective for boys. We have argued that gender-specific patterns of social interactions within the family could be a part of the explanation. Additional data, preferably with information on the intrahousehold allocation of time and other resources, is a prerequisite for moving from suggested explanations to firm answers.

Acknowledgements We thank Melinda Mills and two anonymous referees for helpful comments.

Open Access This article is distributed under the terms of the Creative Commons Attribution License which permits any use, distribution, and reproduction in any medium, provided the original author(s) and the source are credited.

\section{References}

Abbring J, van den Berg G (2007) The unobserved heterogeneity distribution in duration analysis. Biometrika 94:87-99

Adair L, Vanderslice J, Zohoori N (1993) Urban-rural differences in growth and diarrhoeal morbidity of Filipino infants. In: Urban ecology and health in the Third World. Cambridge University Press, Cambridge, pp 75-98

Anh D (1995) Child survival in Vietnam: an investigation of quality of life. Paper presented at the 1995 American Population Association Annual Meeting, San Francisco

Bélanger D, Khuat THO, Liu J, Le TT, Pham (2003) Are sex ratios at birth increasing in Vietnam?. Population 58(2):231-250

Bhalotra S, van Soest A (2008) Birth spacing, fertility and neonatal mortality in India: dynamics, frailty and fecundity. J Econometrics 143(2):274-290

Boerma JT, Bicego GT (1992) Preceding birth intervals and child survival: searching pathways of influence. Stud Family Plann 23(4):243-256

Caldwell J, McDonald P (1982) Influence of maternal education on infant and child mortality: levels and causes. Health Pol Educ 2:251-267

Cebu Study Team (1992) A child health production function estimated from longitudinal data. J Dev Econ 38(2):323-351

Chamarbagwala R (2011) Sibling composition and selective gender-based survival bias. J Popul Econ 24:935-955

Clayton DG (1978) A model for association in bivariate life tables and its application in epidemiological studies of familial tendency in chronic disease incidence. Biometrika 65(1):141-151

Cochrane S, Leslie J, O'Hara D (1982) Parental education and child health: intracountry evidence. Health Pol Educ 2:213-250

Dao LH (2006) Mortality in transitional Vietnam. PhD Thesis, Umeå University Medical Dissertations No. 1036 
Goodkind D (1995) Rising gender inequality in Vietnam since reunification. Pac Aff 68(3): 342-359

Greene W (2003) Econometric analysis, 5th edn. Prentice-Hall, Englewood Cliffs

Guilkey DK, Riphahn RT (1998) The determinants of child mortality in the Philippines: estimation of a structural model. J Dev Econ 56:281-305

Guilmoto CZ, Hoàng X, Ngo Van T (2009) Recent increase in sex ratio at birth in Viet Nam. PLoS ONE 4(2): e4624. doi:10.1371/journal.pone.0004624

Guo G (1993) Use of sibling data to estimate family mortality effects in Guatemala. Demography 30(1):15-32

Guo G, Rodriguez G (1992) Estimating a multivariate proportional hazards model for clustered data using the EM algorithm, with an application to child survival in Guatemala. J Am Stat Assoc 87(420):969-976

Gutierrez RG (2002) Parametric frailty and shared frailty survival models. Stata Journal 2(1):22-44

Gutierrez RG, Carter S, Drukker DM (2001) On boundary-value likelihood-ratio tests. Stata Statistical Bulletin 10(60):15-18

Hobcraft J, McDonald JW, Rutstein S (1983) Child-spacing effects on infant and early child mortality. Popul Index 49(4):585-618

Hobcraft J, McDonald JW, Rutstein S (1984) Socio-economic factors in infant and child mortality: a cross-national comparison. Popul Stud 38(2):193-223

Hobcraft J, McDonald JW, Rutstein S (1985) Demographic determinants of infant and early child mortality: a comparative analysis. Popul Stud 39(3): 363-385

Horton S (1988) Birth order and child nutritional status: evidence from the Philippines. Econ Dev Cult Change 36(2):341-354

Huong DL, Minh HV, Janlert U, Van DD, Byass P (2006) Socio-economic status inequality and major causes of death in adults: a 5-year follow-up study in rural Vietnam. Public Health 120(6):497-504

Lawn JE, Cousens S, Zupan J (2005) 4 million neonatal deaths: When? Where? Why? Lancet 365:891-900

Majumder AK, Islam SMS (1993) Socioeconomic and environmental determinants of child survival in Bangladesh. J Biosoc Sci 25:311-318

Makepeace G, Pal S (2006) Effects of birth interval on child mortality: evidence from a sequential analysis. World Health Popul:1-14

Makepeace G, Pal S (2008) Understanding the effects of siblings on child mortality: evidence from India. J Popul Econ 21(4):877-902

Merli M (1998) Mortality in Vietnam, 1979-1989. Demography 35(3):345-360

Mosley W, Chen L (1984) An analytical framework for the study of child survival in developing countries. Popul Dev Rev 10:25-45 (Supplement: Child survival: Strategies for research)

Nath DC, Land KC, Singh KK (1994) Birth spacing, breastfeeding, and early child mortality in a traditional Indian society: a hazards model analysis. Soc Biol 41(4):168-180

Nguyen-Dinh H, Feeny DH (1999) Are parental characteristics important for child survival? The case of Vietnam. Pac Econ Rev 4(1):1-29

O'Donnell O, Nicolas AL, Doorslaer EV (2009) Growing richer and taller: explaining change in the distribution of child nutritional status during Vietnam's economic boom. J Dev Econ 88(1):45-58

Omariba DWR, Beaujot R, Rajulton F (2007) Determinants of infant and child mortality in Kenya: an analysis controlling for frailty effects. Popul Res Policy Rev 26(3):299-321

Palloni A, Millman S (1986) Effects of interbirth intervals and breastfeeding on infant and early childhood mortality. Popul Stud 40(2):215-236

Pham LT (2009) Determinants of child health and contraceptive use in Vietnam: a microeconometric analysis. $\mathrm{PhD}$ thesis, University of Groningen

Poel EVD, Donnell OO, Doorslaer EV (2009) What explains the rural-urban gap in infant mortality — household or community characteristics? Demography 46:827-850

Rutstein SO, Johnson K (2004) The DHS wealth index. DHS Comparative Reports 6, Calverton, Maryland: ORC Macro

Swenson IE, Thang NM, San PB, Nhan VN, Man VD (1993) Factors influencing infant mortality in Vietnam. J Biosoc Sci 25:285-302

Swenson IE, Thang NM, San PB, Nhan VN, Man VD (1995) Early childhood survivorship in Vietnam. J Trop Med Hyg 98:204-208 
Trussell J, Hammerslough C (1983) A hazards-model analysis of the covariates of infant and child mortality in Sri Lanka. Demography 20:1-26

van der Klaauw B, Wang L (2011) Child mortality in rural India. J Popul Econ 24:601-628

UNFPA (2009) Recent change in the sex ratio at birth in Vietnam. Hanoi: UNFPA Viet Nam

Vaupel JW, Manton KG, Stallard E (1979) The impact of heterogeneity in individual frailty on the dynamics of mortality. Demography 16(3):439-454

Wagstaff A, Nga NN (2002) Poverty and child survival prospects of Vietnamese children under Doi Moi. Policy Research Working Paper, World Bank 